\title{
Correlations between Distribution of Producer Services and Urban Built Environment in Metro Station Areas: A Case of Xi'an, China
}

\author{
Qi Zhang $\mathbb{D}^{1,2}$ Yu-Jie Zhang $\mathbb{D}^{1}{ }^{1}$ Xin Ding, ${ }^{1}$ and Qiu-Ping Wang ${ }^{1,2}$ \\ ${ }^{1}$ School of Civil Engineering, Xi'an University of Architecture and Technology, Xi'an 710055, China \\ ${ }^{2}$ National Experimental Teaching Center for Civil Engineering Virtual Simulation (XAUAT), Xi'an 710055, China \\ Correspondence should be addressed to Qi Zhang; zhangqi-xauat@163.com
}

Received 6 December 2021; Accepted 3 February 2022; Published 28 February 2022

Academic Editor: Song-He Wang

Copyright (c) 2022 Qi Zhang et al. This is an open access article distributed under the Creative Commons Attribution License, which permits unrestricted use, distribution, and reproduction in any medium, provided the original work is properly cited.

Since impacts of rail transit on urban industries and space most obviously appear in metro station areas, correlations between the spatial distribution of producer services and urban built environment in metro station areas are studied in Xi'an, China. At first, the scope determining methods of a metro station area were separately proposed for both single-line station and multiline transfer station based on their construction and transportation modes. Then, when the producer services were divided into 6 categories of business, POI numbers of enterprises of each category in metro station areas were collected and weighted to calculate the distribution intensity for categories. Finally, on condition that the urban built environment of a metro station area included job and residence space, outdoor activity space, and municipal road space, correlation performances between the distribution intensity of categories and indexes representing 3 space elements of the built environment were calculated through second-order partial correlation analysis, while the corresponding mechanisms of correlations were explained too. The main conclusions of this paper indicate that there are significant positive correlations between the distribution intensity and the diversity index of job and residence space for most categories, whereas significant negative correlations between it and the openness index of outdoor activity space for most categories. Moreover, positive but weak correlations were appeared between the distribution intensity and the street network density index of municipal road space only for categories of intermediary consulting and leasing.

\section{Introduction}

Modern rail transit system is not only a convenient and efficient urban traffic tool but also an impetus to urban economic development. According to many studies over the world, the economic functions of rail transit systems have mainly referred to quasipublic products, positive externalizations, and economies of scale [1], while the variation and transformation of urban industrial structure and spatial structure have been deeply influenced by the rail transit system [2]. Metro station is the only operating node of the rail transit system connecting to other urban physical surroundings, so impacts of rail transit on urban industries and space firstly and most obviously appear in metro station areas [3], and industrial distribution in metro station areas is regarded as one of the most important research topics at a small scale in economic geography and urban planning. It is reported that an urban built environment around a traffic station always affects the staying time and experience of people who pass by it [4]. Accordingly, the better built environment a metro station area has, faster trips and more visits there will be both for businesses and personals [5] so that one kind of beneficial location condition is created for modern industries to survive and develop in this area. Therefore, improving the quality of the urban built environment is generally considered an effective approach to reach a successful TOD in the metro station area [6], while it also makes the space usage more intensive and efficient by industrial sectors clustering hereby and promotes urban economic growth on the whole. By the way, although the spatial distribution of most urban industries is closely correlated to their urban built environment [7], huge differences of correlation performances still appear for various industrial sectors in metro station areas. The nice built 
environment surely enhances the distributing scales of commercial sectors in these areas [8], but it strongly drives factories moving away from them [9]. In contrast, correlation can seldom be found between the built environment and the public service facility distributions in metro station areas [10].

Through literature analysis, it is believed that the correlation between the urban built environment and the industrial distribution in metro station areas is full of significance, and corresponding research studies are rich in both theories and cases. However, a lot of remaining issues are ready to be studied in the long-term future because the categories of modern industrial sectors are complex and diversified. Since the producer service is now playing an increasingly dominant role in urban economies [11] and their spatial development mechanisms are quite different from those of retail commerce and common offices, correlations between the spatial distribution of producer services and urban built environment in metro station areas are studied by a case of Xi'an, China. Furthermore, both empirical reference and planning guidance can be provided to future spatial developing policies of producer services in metro station areas with outcomes gained in this paper.

\section{Metro Station Areas}

2.1. Scope Determining Methods of a Metro Station Area. The scope determining methods of a metro station area are proposed as following based on some relevant research studies.

\subsubsection{Scope Determining for a Single-Line Station.} Producer services are basically laid out in urban commercial and office buildings, while related research shows that [12] such buildings are usually distributed within a circle of $400 \sim 600 \mathrm{~m}$ radius from the center of the metro station site. At the same time, physical traffic activities generated by the producer services mainly depend on walking travels of pedestrians within a metro station area. According to some transportation research, [13] it is believed that the acceptable travel distance for most pedestrians is $600 \sim 900 \mathrm{~m}$, while the ratio between the actual walking distance of metro passengers from their departure/arrival to the station center and straight-line distance of them is 1.53 on average in China by a recent research study [14]. In terms of this ratio, the straight-line distance can be converted to $392 \sim 588 \mathrm{~m}$ for walking activities from the metro station center. Through the above analysis of buildings' distribution and pedestrians' walking, it is determined that the area of a single-line metro station is a circular surface with a $500 \mathrm{~m}$ radius from the station center in this paper.

\subsubsection{Scope Determining for a Multiline Transfer Station.} When an urban metro system develops into a network stage, it is necessary to set up a transfer station at the intersections of different crossing lines for passenger transferring. The transferring modes include same point transfer and passage transfer. Same point transfer means that only one station building is constructed and used for all the crossing lines. For same point transfer, the scope of a station area is similar to a single line station because of its short transferring distance and high efficiency. Passage transfer means that various station buildings are constructed separately for crossing lines due to complex terrain features and existing surface and underground structures; then, these station buildings are connected by one or more passages for using together as a whole transfer station. For passage transfer, the scope of station areas may change largely by the length and complexity of its transferring passages.

With the help of transferring passage length recommended by some designing standards of rail transit engineering, methodological types for scope determining of a multiline transfer station area are put forward as follows:

TYPE A: same point transfer station. The condition of being the same point one includes that only one coordinate on the electronic map can be collected for its building position, and its scope determining is the same as that of the single line station.

TYPE B: short-passage transfer station. The conditions of being a short-passage one include that two or more coordinates on the electronic map can be collected for its building positions and DC (the nearest straight-line distance between any two collected coordinates) $\leq 100 \mathrm{~m}$ (walking distance $\leq 150 \mathrm{~m}$ ). For its scope determining, all collected coordinates are connected to each other to form a straight line or a polygon firstly. Then, a circular surface with a $600 \mathrm{~m}$ radius from the midpoint of the straight line or geometric center of the polygon is considered the area of a short-passage metro station. As shown in Figure 1.

TYPE C: long-passage transfer station. The conditions of being a long-passage one include that two or more coordinates can be collected for its building positions and DC (the nearest straight-line distance between any two collected coordinates) $>100 \mathrm{~m}$ (walking distance $>150 \mathrm{~m}$ ). For its scope determining, several circular surfaces with a $400 \mathrm{~m}$ radius from every coordinate are formed separately at first so that their surface union is considered the area of a long-passage metro station then, as shown in Figure 2.

2.2. Metro Station Areas in Xi'an. Xi'an is a world-famous ancient cultural capital and one of the national central cities of China. In December 2019, there was a total operating length of 126.35 kilometers of Xi'an Metro (https://www. xianrail.com/), which went through the main districts and connected most of the internal and external transportation hubs in this city. There were also a total of 89 stations of Xi'an Metro at that moment, including 6 transfer stations.

According to the above scope determining process of transfer station areas, the coordinates of each transfer station are located, while distances between any two coordinates are measured and compared to ensure its DC and scope type. Thus, 6 transfer metro station areas in Xi'an are determined by their own types, and the results are shown in Table 1. 


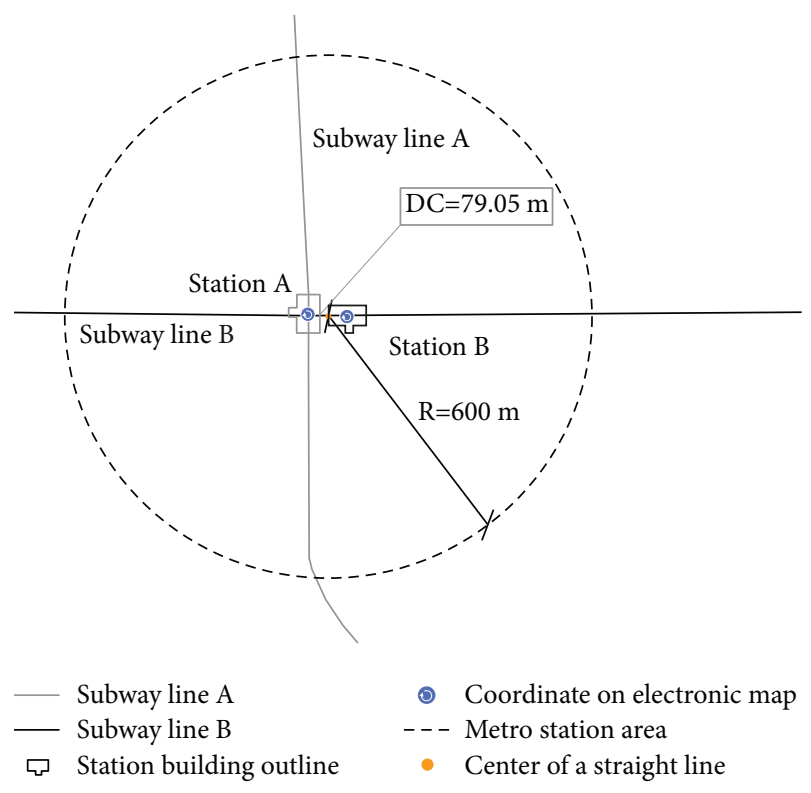

Figure 1: Area of a short-passage transfer station.

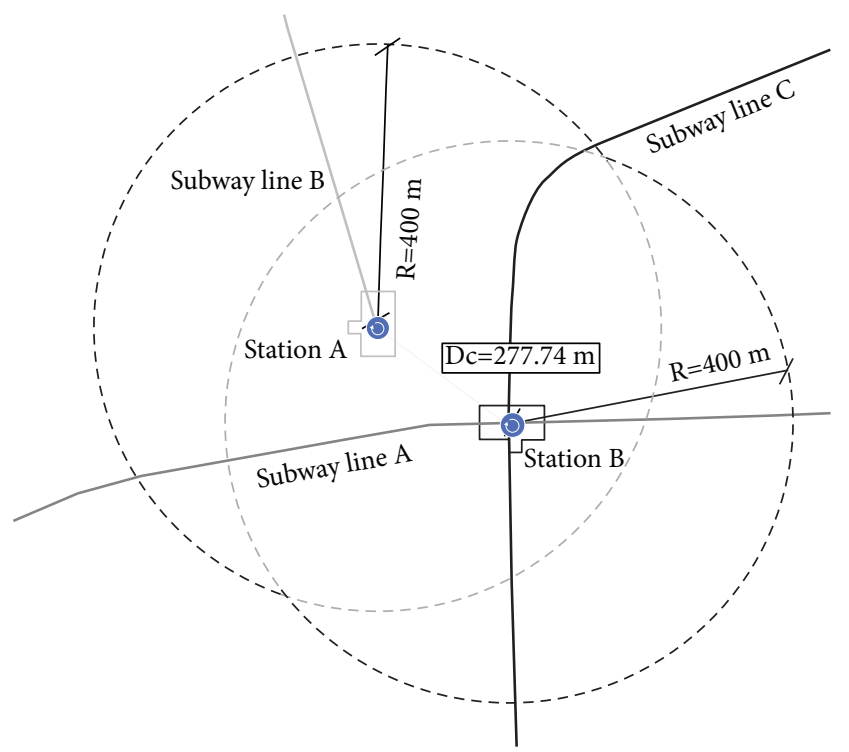

- Subway line A

- Subway line B

- Subway line C

$\square$ Coordinate on electronic map

- - Metro station area

- Center of a straight line

Figure 2: Area of a long-passage transfer station.

For the other 83 single-line stations of Xi'an Metro, their metro station areas are the circular surfaces with $500 \mathrm{~m}$ radius from the center of each station coordinate. Therefore, all of the metro station areas in Xi' an can be gained, as shown in Figure 3.

\section{Distribution of Producer Services}

3.1. Employment of Points of Interest Data. There have been lots of research achievements about the spatial distribution of producer services on a macroscale $[15,16]$. However, a few case studies on the distribution of these industrial sectors have been reported on a microscale at present due to two limitations of data collection, as well as investigation. One is that a common sample survey is not sufficient enough to establish research data since the classification of producer services is complex and their enterprise volume is very large. Another one is that building information is always too late to describe producer service activities because of their inherent flexibility from light assets while sharing uses or alternating uses in a short time of commercial offices (floors) within the same building are often happened for them.

So, point of interest (POI) data is employed in this paper to detect the distribution of producer services in order to settle the above limitations. POI data is now a widespread used spatial data source, which obtains all of real-time information data of any one point of interest on the electronic map platform through the batch search of relevant keywords, including longitude, latitude, and address [17]. As the completeness, timeliness, and accuracy of the geographical description to industrial locations on a microscale can be effectively improved by POI, it is suitable for detecting the distribution of producer services in metro station areas in $X i$ 'an rather than data from a full enterprise sample surveying or a building information surveying.

3.2. Categories of Producer Services. The producer services were divided into 10 major types in terms of Classifying Standard issued by the National Bureau of Statistics of China (NBSC) in 2019, accompanied with 35 medium ones and 171 minor ones. 16 medium types mostly acting in urban space from the above Standard were selected and integrated into 6 categories of business in this paper. They were e-commerce, finance and insurance, scientific research and design, logistics, intermediary consulting, and leasing, as shown in Table 2.

Since categories of producer services had different scale effects and multiplier effects in the urban economy, POI numbers of enterprises of each category should be weighted to reflect their different importance of distribution. The weights for categories were determined based on the weight classification table of service facilities [18] and their applications in China [19], as shown in Table 2.

\subsection{Distribution Intensity of Categories in Xi'an.} Keywords of 6 categories in Xi'an city on December 8, 2019, were collected from the open port platform of AutoNavi map (https://lbs.amap.com/) with the help of Python programming. At the same time, the keyword exclusion method was used to clear the collected data so that the ones that did not belong to producer services were removed from the entry. As a result, 14,071 pieces of POI data of 6 categories were finally gained from Amap, as shown in Table 2. Each piece of data contained unique ID, name numbering, address latitude and longitude, administrative region, and other attribute information.

Both the cleared POI data of each category and the 89 metro station areas in $\mathrm{Xi}$ an were located together on the ArcGIS10.5 platform so as to show the basic distributions of 6 categories in metro station areas in Xi'an, as shown in Figure 4 . 
TABLE 1: DC and scope type of 6 transfer stations of Xi'an Metro.

\begin{tabular}{llcr}
\hline Transfer station & Intersecting lines & DC $(\mathrm{m})$ & Types for scope determining \\
\hline Beidajie & Metro line 1/line 2 & 0.00 & TYPE A \\
Tonghuamen & Metro line 1/line 3 & 79.72 & TYPE B \\
Xiaozhai & Metro line 2/line 3 & 0.00 & TYPE A \\
Wulukou & Metro line 1/line 4 & 51.80 & TYPE B \\
Xingzhengzhongxin & Metro line 2/line 4 & 0.00 & TYPE A \\
Dayanta & Metro line 3/line 4 & 73.48 & TYPE B \\
\hline
\end{tabular}

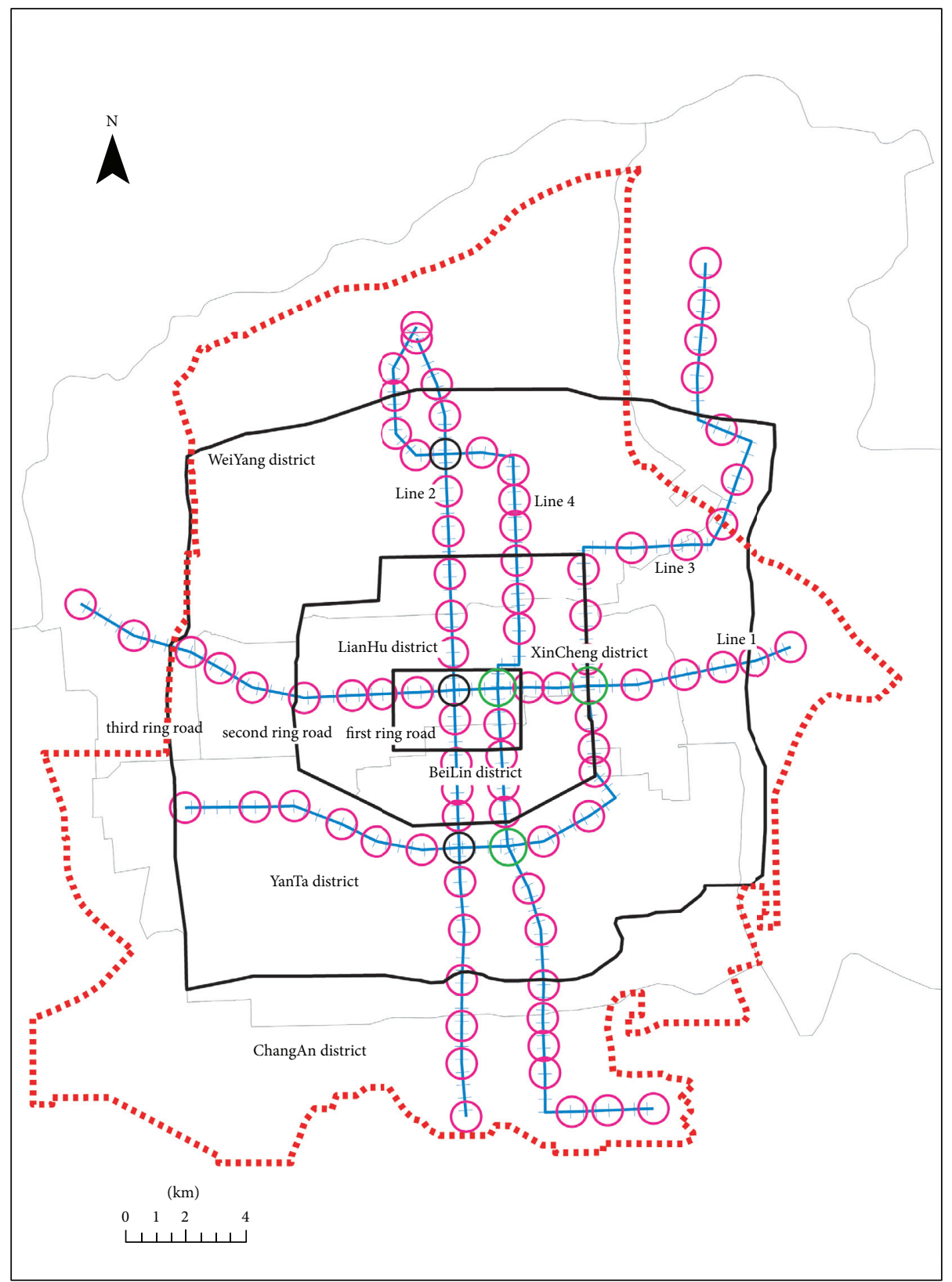
... . . Boundary of master planning of Xian
Short-passage transfer stations
City ring roads
+ Subway lines
Single line stations
Boundaries of municipal districts
Same point transfer stations

Figure 3: All metro station areas in Xi'an. 
TABle 2: Categories of producer services and their POI in Xi'an.

\begin{tabular}{|c|c|c|c|c|}
\hline $\begin{array}{l}\text { Medium type code/named by } \\
\text { NBSC of China }\end{array}$ & Category & $\begin{array}{c}\text { POI } \\
\text { numbers } \\
\text { (pieces) }\end{array}$ & $\begin{array}{l}\text { Relevant keywords in coding table from open port } \\
\text { platform of Amap }\end{array}$ & $\begin{array}{l}\text { Weight for } \\
\text { category }\end{array}$ \\
\hline $\begin{array}{l}\text { 031/Information transmission } \\
\text { service } \\
\text { 032/Information technology } \\
\text { services } \\
\text { 033/e-commerce support } \\
\text { services }\end{array}$ & E-commerce & 1067 & $\begin{array}{l}\text { Fixed telecommunications, mobile } \\
\text { telecommunications, internet access, information } \\
\text { technology consulting, integrated circuit design, } \\
\text { internet platform, and telecommunication business } \\
\text { hall }\end{array}$ & 0.9 \\
\hline
\end{tabular}

041/Monetary and financial services

042/Capital market services

Finance and insurance

043/Productive insurance

services

011/R\&D and design services 014/Standard measurement service for inspection, testing, and certification

Scientific research and design Scientific, educational, and cultural services

015/Productive professional technical services

025/Handling, packing, and agency services 026/National postal and express Logistics 5,010 Handling, packaging, cargo transport agency, postal, express, and delivery

services

012/Transformation services for

scientific and technological

achievements

013/Intellectual property rights

and related legal services

072/Consulting and investigation

Intermediary consulting
Technical promotion service, science and technology intermediary, intellectual property, productive law, accounting, auditing, taxation, business consulting service, advertising, market management service, translation service, and credit service

073/Other productive business

services

062/In-kind rental service

Leasing

671

14,071

Then, the distribution intensity of each category in a metro station area was calculated with their POI data and corresponding weights by the following formula:

$$
x=q_{\mathrm{ij}} / q_{j} .
$$

In the above formula, $x$ is the distribution intensity, $q_{i j}$ is the weighted POI numbers of category $j$ in a station area $i$, and $q_{j}$ is the total ones of category $j$ in all metro station areas in Xi'an $(i=1 \sim 89, j=1 \sim 6)$.

\section{Correlations between Distribution and Built Environment}

\subsection{Methods of Correlation Analysis}

4.1.1. Principles of Correlations. On the one hand, industrial development and its distribution within metro station areas will be differentiated due to the local construction quality level of the urban built environment. High accessibility in metro station areas not only reduces travel time cost but also brings about land appreciation and building rent premium. Thus, industrial sectors with high returns will be more suitable to be located here according to the theory of competitive rent [20]. Similarly, excellent construction standards and supporting facilities of office buildings will also be essential to locating industrial sectors with high returns [21]. Generally speaking, modernized and high-level construction quality of built environment promotes more sectors with high returns to locate in metro station areas, whereas backward construction quality hinders sectors to locate in. In addition, because there are obvious variations of operating costs and benefits in different high-return industries, industries also have different affordable rent levels when seeking for office buildings in metro station areas [22]. Accordingly, the differentiation of the rent level makes the space demand of office buildings in areas never be equally satisfied for different industries. Therefore, spatial competitions within metro station areas have unavoidably happened among high-return industries through market actions, and the winner will get the right of building space usage.

On the other hand, industrial development and its distribution within metro station areas will be differentiated due to space usage patterns of the urban built environment. 


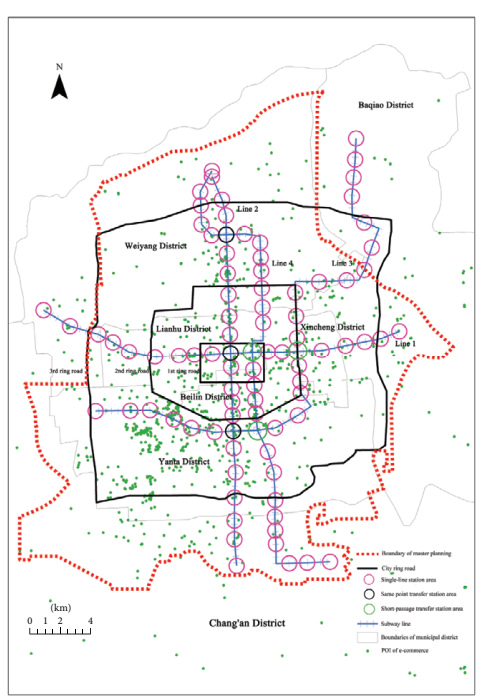

(a)

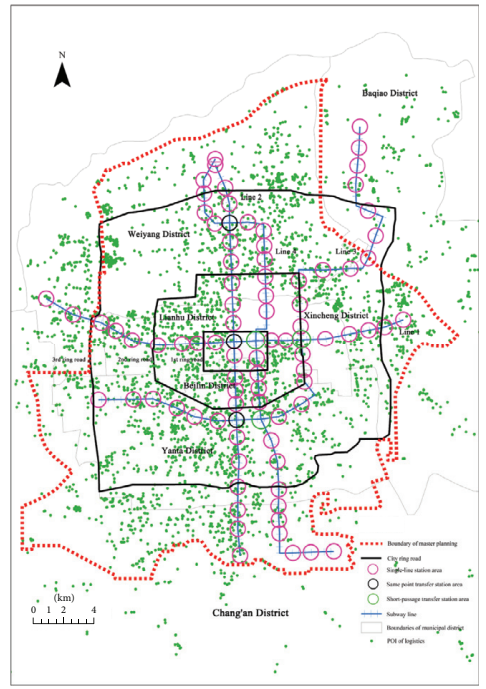

(d)

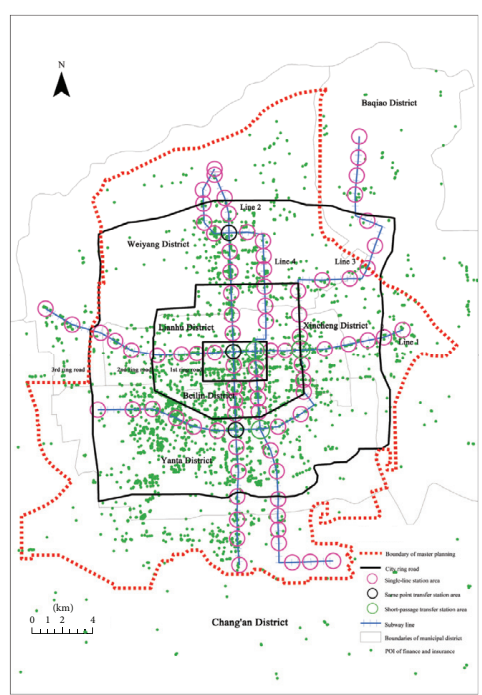

(b)

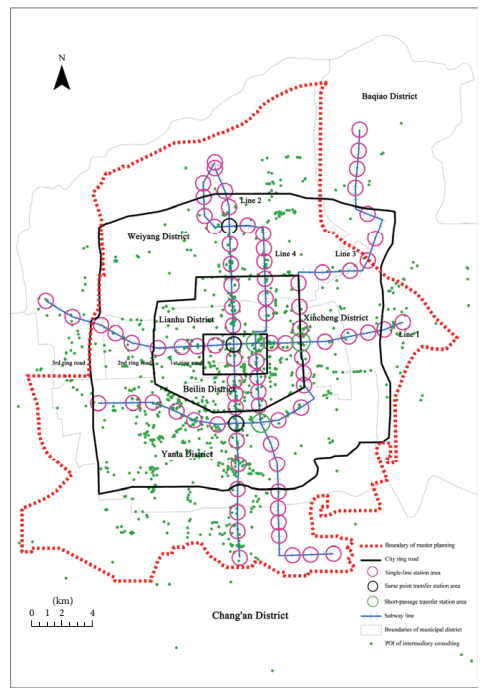

(e)

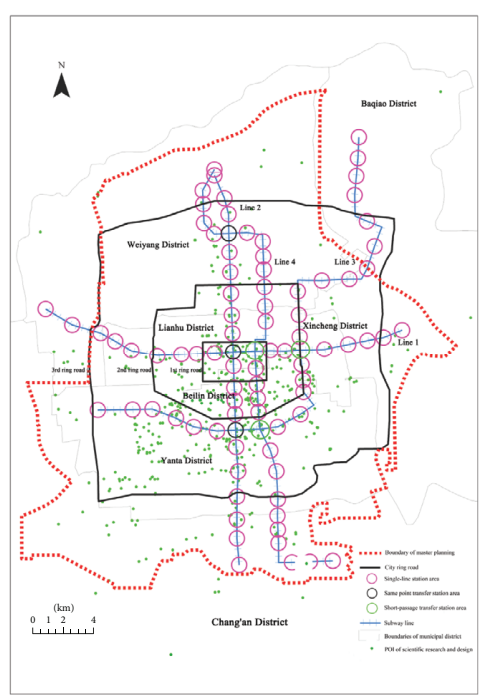

(c)

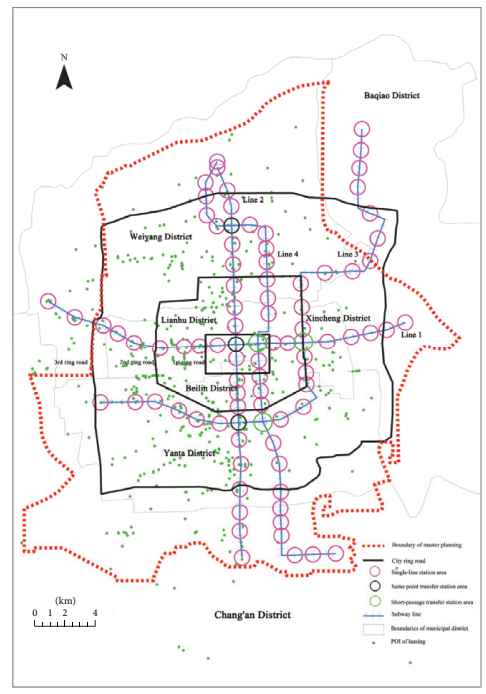

(f)

Figure 4: POI distributions of 6 categories of producer services in Xi'an. (a) E-commerce. (b) Finance and insurance. (c) Scientific research and design. (d) Logistics. (e) Intermediary consulting. (f) Leasing.

Metro station areas are places where various flows of economic elements converge together, so both land use and buildings hereby tend to be developed in a very high-density status [23]. However, a high-density usage pattern should not be undertaken by a single or a few very similar industrial sectors in metro station areas. Otherwise, an excessive polarization of elements integrated by these sectors or even overload may appear in a short term due to the homogeneity of the industrial chain, which often leads to adverse effects (traffic congestion, environmental pollution, inefficient information, etc.) that reduce the efficiency of industrial allocation. On the contrary, diversified usage patterns by a lot of industrial sectors are conducive to balance their demands of industry and transportation in metro station areas at different times [24], under which each sector should make proper use of land and buildings according to its own demands. Therefore, overloaded development can be avoided, and the efficiency of industrial allocation can be improved through intensive cooperation on an industrial chain in metro station areas.

In summary, these two principles of correlations between industrial distribution and built environment within metro station areas are theoretically introduced and practically adopted in the case study below.

4.1.2. Built Environment of Areas in Xi'an. Urban built environment is created by humans and made of various artificial elements. Its formation not only relies on patterns of human production and lifestyle but also affects all kinds of 
human activities in itself. According to the working or living patterns and activity intensities, the urban built environment of a metro station area was divided into 3 space elements in this paper so as to carefully explain distributing activities of producer services hereby. These elements included job and residential space, outdoor activity space, and municipal road one, while their calculating methods are as follows:

(1) Job and residential space.

Diversity index is used to analyze this element, and the calculation formula is

$$
D=1-\sum\left(\frac{\mathrm{N}_{l}}{N-\left(\mathrm{N}_{O}+\mathrm{N}_{R}\right)}\right)^{2} \sum \text { among them: } N=\sum \mathrm{N}_{l}+\mathrm{N}_{O}+\mathrm{N}_{R} \text {. }
$$

In the above formula, $D$ is the diversity index. $N$ is the total size of developed land in a metro station area. $N_{l}$ is the land size for any planned spatial function $l$ of jobbing or living in this area. When the function number is $n, l=1 \sim n$. $N_{O}$ is the land size for all planned spatial functions of outdoor activities in this area, such as green lands, squares, parks, and water bodies. $N_{R}$ is the land size for all planned spatial functions of municipal roads in this area.

(2) Outdoor activity space.

Openness index is used to analyze this element, and the calculation formula is

$$
K=\frac{\mathrm{N}_{O}}{N}
$$

In the above formula, $K$ is the openness index, and other symbols have the same meanings as formula (2).

(3) Municipal road space.

Street network density index is used to analyze this element, and the calculation formula is

$$
P=\frac{L}{N}
$$

In the above formula, $P$ is the street network density index. $L$ is the total length of municipal roads in the area, and the other symbols have the same meanings as formula (2).

\subsection{Results of Correlation Analysis}

4.2.1. Calculations of Correlations. Basic data about 3 space elements of the built environment was obtained through the land use planning and transportation system planning of Xi'an downtown issued by Xi'an Natural Resources and Planning Bureau. Then, the satellite images of metro station areas taken from the AutoNavi map were compared with the basic data from planning. If there were some obvious differences between them, on-site investigations should be carried out for further supplementary and calibration in order to grasp the developing status of the built environment accurately. In addition, 8 metro station areas outside the planning scope of Xi'an downtown were excluded from the next analysis of the built environment due to their nonofficial planning procedures and results.

All the basic data about 3 space elements of 81 remaining metro station areas in Xi'an were obtained with the help of the above steps. The diversity index $D$ in each area was then calculated by using equation (2), openness index $K$ by (3), and street network density index $P$ by (4).

Since the length of the paper was limited, the calculation results of built environment of metro station areas in Xi'an were only listed with 4 examples, as shown in Table 3 .

Any one of 81 metro station areas in Xi'an was used as a study sample for correlation analysis, where the distribution intensity of a certain category of producer services was used as the dependent variable, and indexes $D, K, P$ of built environment hereby were correspondingly used as the independent variables. Meanwhile, since the total developed land of a metro station area consisted of job and residence space, outdoor activity space, and municipal road space based on formula (2), a collinear relationship surely existed among $\sum N_{l}, N_{O}$, and $N_{R}$ in an area. So, a measuring tool for second-order partial correlation analysis would be adopted to calculate the coefficient in this paper so that drawbacks of collinearity among independent variables could be avoided. [25].

The calculation formula of all samples by using a secondorder partial correlation tool is as follows:

$$
r_{x, 1,2,3}=\frac{r_{x, 1,2}-r_{x, 3,2} \cdot r_{1,3,2}}{\sqrt{1-r_{x, 3,2}^{2}} \cdot \sqrt{1-r_{1,3,2}^{2}}}
$$

In the above formula, $x$ is the distribution intensity of any one of 6 categories of producer services in metro station areas. $r$ is the second-order partial correlation coefficient between $x$ and index marked 1 expressing one of the three space elements of the built environment when the other two indexes marked 2 and 3 are controlled. When 1 is set as $D, 2$ and 3 are set as $K$ and $P$; when 1 is set as $K, 2$ and 3 are set as $P$ and $D$; when 1 is set as $P, 2$ and 3 are set as $D$ and $K$. Other symbols have the same meanings as equations (1) (4).

By formula (5), the strength and direction of net correlation between a target-dependent variable $x$ and an independent variable index were shown through the calculating value of coefficient $r$ at a prescribed significance level, as well as its plus sign or minus one. If the value of coefficient was large with a plus sign, the higher the positive correlation between distribution intensity of category and 
TABLE 3: Indexes of built environment of some metro station areas in Xi'an.

\begin{tabular}{lcccc}
\hline Station & Line $(\mathrm{s})$ & $D$ & $K$ & $P$ \\
\hline Zhonglou & Line 2 & 0.5775 & 0.0212 & 0.0092 \\
Dayanta & Line 3, line 4 & 0.7140 & 0.1678 & 0.0063 \\
Chanhe & Line 1 & 0.8683 & 0.4434 & 0.0059 \\
Shizhongyiyiyuan & Line 4 & 0.5855 & 0.0836 & 0.0067 \\
\hline
\end{tabular}

this index of the built environment was. On the contrary, the negative correlation between distribution intensity and index was higher when the value was large with a minus sign.

For 81 samples of metro station areas in Xi'an downtown, the second-order partial correlation coefficients between distribution intensity $x$ of each one of 6 categories and each index of $D, K$, and $P$ were completely done through 6 groups of calculations by (5). The results are shown in Table 4.

4.2.2. Explanations to Correlations. The correlation performances between the distribution intensity of each category and index $D$ are analyzed, respectively, and compared comprehensively by rows of Table 4 and so does index $K$ and index $P$. Generally speaking, the correlation mechanisms between distribution and space elements of the built environment in metro station areas are explained as follows:

(1) Significant Positive Correlations between the Distribution Intensity and Diversity of Job and Residence Space for Most Categories. On the whole, the constructions of the job and residential space are small in scale but good in quality based on the developing mode of office buildings within metro station areas. As typical industrial sectors with intensive knowledge, technology, and innovation, producer services need office buildings with a less scale but more premium decorations and in-house facilities for their daily operating, as well as high-accessible urban locations. Therefore, lots of producer services are attracted to clusters in metro station areas where locational advantages of jobbing and living are more obvious than other urban localities. What is more, because most sectors of producer service have a very wide range of industrial connections, many other sectors associated with them on industrial chains are apt to cluster near the locations of producer services. So, the more diversified development of job and residence space in a metro station area, the more varieties of office buildings can be constructed not only for the uses of producer services themselves but also for associated sectors on their industrial chains. In a word, all industries will benefit from the intensive sharing distribution in the metro station area, which leads to both wellserved operations and industrial agglomerations.

The detailed explanations to correlations between the distribution of each category and job and residence space are as follows:

The largest positive and significant correlation coefficient was detected in the category of scientific research and design (0.436), and the reasons lie in its strong and multidirectional physical industrial linkages. Enterprise kinds linked with this category on industrial chains mainly include exploration and mapping, special equipment, printing and publishing, science exhibition and advertisement, and catering and accommodation. All of them expect to make a shorter trip of materials handling to or from enterprises of scientific research and design and contact their personnel conveniently through face-to-face visiting. Therefore, it is believed that the diversity of job and residence space surely helps these linked enterprises share suitable buildings in metro station areas so that their handling and visiting trips are shortened as far as possible.

The correlation coefficients were positive and significant, but the values were correspondingly reduced in the categories of intermediary consulting (0.244), finance and insurance (0.237), and e-commerce (0.213). Although enterprises of these categories also have strong industrial linkages, parts of their servicing products can be chiefly presented by information technology with digital and standardized forms. So, these categories will often communicate with the linked enterprises on industrial chains by Internet or telecommunications besides handling and visiting, while the requirement of being located in diversified job and residence space is true but declining for these categories.

The correlation coefficients were not significant in the categories of logistics and leasing. The components of logistics production chain include collection, transportation, storage, sorting, and delivery. Only some collection and delivery to initial and terminal clients can be located in metro station areas because of their little use of warehouses and transportation facilities, while other components ought to be close to urban freight hubs in suburban districts where a large number of warehouses and transportation facilities have already constructed. Similarly, since leasing subjects in producer services generally have high value or large volume, only stores responsible for soliciting leasing clients and marketing can be located in metro station areas. Other components of the leasing production chain ought to be far from metro stations, such as storage and maintenance.

\section{(2) Significant Negative Correlations between the Distribution} Intensity and the Openness of Outdoor Activity Space for Most Categories. On the whole, because the total land of a metro station area is limited, the share of land left for industrial development will be smaller when more outdoor activity spaces have developed in it, such as greening, squares, parks, and water bodies. By the way, metro station areas with both high accessibility and good nature surroundings become one of the best places for leisure and entertainment activities in urban districts and suitable for consumer services to gather their main target clients through access advantages. Therefore, on the one hand, large volume sectors of consumer services are always apt to locate in hereby, such as catering, shopping, entertainment, hotel, and fitness. On the other hand, although producer services also expect a better natural environment and living facilities for attracting talents to join in, their strong recruitment competitiveness of human resources still rely on sustainable entrepreneurial conditions and good salaries intrinsically. 
TABLE 4: Coefficient results of second-order partial correlation.

\begin{tabular}{|c|c|c|c|c|c|c|c|}
\hline \multicolumn{2}{|c|}{ Second-order partial correlation } & \multicolumn{6}{|c|}{ Dependent variable $x$} \\
\hline \multicolumn{2}{|c|}{ Categories } & E- & Finance and & Scientific research & Logistics & Intermediary & Leasing \\
\hline $\begin{array}{l}\text { Controlling } \\
\text { variables }\end{array}$ & $\begin{array}{c}\text { Independent } \\
\text { variable }\end{array}$ & Group 1 & Group 2 & Group 3 & Group 4 & Group 5 & $\begin{array}{c}\text { Group } \\
6\end{array}$ \\
\hline$K, P$ & $D$ & $0.213^{*}$ & $0.237^{* *}$ & $0.436^{* * *}$ & 0.039 & $0.244^{* *}$ & -0.041 \\
\hline$P, D$ & $K$ & $-0.379^{* * *}$ & $-0.438^{* * *}$ & $-0.521^{* * *}$ & $-0.372^{* * *}$ & $-0.342^{* * *}$ & -0.057 \\
\hline$D, K$ & $P$ & -0.005 & 0.119 & 0.113 & -0.180 & $0.247^{* *}$ & $0.219^{* *}$ \\
\hline
\end{tabular}

Note. ${ }^{* * *}$ means being significant at the 0.01 level, ${ }^{* *}$ means being significant at the 0.05 level, and ${ }^{*}$ means being significant at the 0.1 level.

As a result, the more land size of outdoor activity space in a metro station area, the less developing land left for both producer services and consumer services will be, whereas more flows of clients will become increasing only for the consumer one. So, consumer services are much more competitive than producer services in building renting investments in metro station areas with high openness under the game strategies of spatial resources dominated by the market economy.

The detailed explanations to correlations between the distribution of each category and outdoor activity space are as follows:

The largest two negative and significant correlation coefficients were detected in the categories of scientific research and design $(-0.521)$ and finance and insurance $(-0.438)$. Specific laboratories for experimental testing and inspecting are necessities to support researching and designing on their production chains so that more quantity demands of floor areas of office buildings generate in this category. In addition, convenient and efficient services for clients are essences of enterprises in the category of finance and insurance. Thus, they must prefer a ground floor within office buildings directly toward streets so that more quality demands of floor areas generate in this category. It is suggested that scientific research and design and finance and insurance are the most vulnerable categories under the spatial competition between producer services and consumer services where the openness of outdoor activity space is high.

The quantity and quality demands of office buildings for other categories are true but less. So, the extent to which they are driven away from the areas with high openness by consumer service due to spatial competition gradually decreases and even disappears, while the correlation coefficients of these categories correspondingly become lower or even not significant.

(3) Positive but Weak Correlations between the Distribution Intensity and the Street Network Density of Municipal Road Space Only for Categories of Intermediary Consulting and Leasing. The servicing products of intermediary consulting have nonstandardized characteristics typically, while frequent face-to-face contacts between its service providers and customers are still required to establish the trust of business and reach personalized solutions then. Meanwhile, the travel proportions of rail transit in all transportation modes are $20 \%$ or less in large and medium-sized cities according to a recent research study in China [26]. So travels for face-toface contacts on the production chain of intermediary consulting heavily rely on various patterns of streets in metro station areas, on which motor vehicles and non-motor ones run smoothly. Therefore, the greater the street network density in a metro station area, the better travel conditions for enterprises of intermediary consulting may be hereby.

Since the leasing subjects are generally of high values, clients almost never purchase such services only through online channels. For a prudent management attitude, they tend to negotiate with service providers through face-to-face contacts after online screening to finalize the order. Similarly, the greater the street network density in a metro station area, the better travel conditions for enterprises of leasing may be.

Except for the above two, frequent face-to-face contacts with personnel are seldom needed in other categories of producer services. Thus, there is little significant correlation between their distribution intensity and municipal road space in metro station areas.

\section{Conclusions and Suggestions}

Metro station areas in Xi'an, China, were determined, and POI data of 6 categories of producer services were empirically detected at the beginning of this study. Then, correlated spatial interactions between the distribution of each category and the space elements of urban built environments in these areas were carefully analyzed according to the calculation of second-order partial correlation coefficients.

The main conclusions include the following correlation mechanisms:

Complementary mechanism. Producer services need office buildings with a less scale but more premium facilities and high-accessible urban location, while many other sectors associated with them on industrial chains are apt to cluster together within metro station areas so as to achieve complementary development and agglomeration economy through intensive close-range connections. Thus, there are significant positive correlations between the distribution intensity and the diversity of job and residence space for most categories.

Competitive mechanism. The more openness of a metro station area, the less developing land for both producer services and consumer services will be left, whereas more flows of clients will become increasing only for 
consumer one. So consumer services are much more competitive than producer services in buildings renting investments hereby, and there are significant negative correlations between the distribution intensity and the openness of outdoor activity space for most categories.

Selected supporting mechanism. On condition that more and more travels of people and goods in producer services are substituted by information technologies as a whole, only a few travels on municipal streets are preferred by categories of intermediary consulting and leasing in order to support their frequent face-to-face contacts with personnel. So, there are positive but little weak correlations between the distribution intensity and the street network density of municipal road space for these two categories.

Based on the above three mechanisms, urban planning suggestions on the built environment in metro station areas are separately developed for the newly constructed stations in Xi'an Metro for the future five years. Thus, producer services hereby can be better layout and operated. Firstly, by using the complementary mechanism, more attention should be paid to diversify the use of commercial and office lands in the area of the new metro stations in districts where important urban industrial growth poles are located, as well as the supplies of various infrastructures. Therefore, more and more related enterprises are apt to select these metro station areas as their office sites, while high-quality producer services will cluster together around their industrial chain. Secondly, by using the competitive mechanism, more public squares and greening lands should be planned and finished in the new metro station areas beside which important natural and cultural scenic spots exist, while the development of consumer services facilities should also be appropriately increased hereby. On the contrary, it is necessary to make the producer service leave for some other new metro station areas so as to avoid its inefficient spatial competition with consumer one. Thirdly, by using the selected supporting mechanism, a lot of producer service enterprises whose productions are highly dependent on intensive transportation through municipal roads are suitable to be planned in the new metro station areas in developing suburban industrial districts. As result, both the number of permanent residents and employment opportunities will greatly increase at those districts attributed to strong economic driven forces provided by newly coming producer service enterprises.

\section{Data Availability}

The data used to support the findings of this study are available from author upon request.

\section{Conflicts of Interest}

The authors declare that they have no conflicts of interest.

\section{Acknowledgments}

This work was financially supported by the Social Science Foundation of Shaanxi Province, China (grant no. 2018S39).

\section{References}

[1] R. Cervero and J. Murakami, "Rail and property development in Hong Kong: experiences and extensions," Urban Studies, vol. 46, no. 10, pp. 2019-2043, 2009.

[2] E. Guerra, "Mexico City's suburban land use and transit connection: the effects of the Line B Metro expansion," Transport Policy, vol. 32, pp. 105-114, 2014.

[3] J. X. Hu, M. Zhu, L. J. Pu, and F. F. Cai, "Progress of the research on the influence of traffic road on regional land use change," Resources and Environment in the Yangtze Basin, vol. 27, no. 1, pp. 205-214, 2018.

[4] T. Li, H. Jiang, P. Jing, and M. Zhang, "Analyzing the coordination relationship between urban built environment and traffic level," Journal of Advanced Transportation, vol. 2021, Article ID 9952306, 11 pages, 2021.

[5] M. S. Mohammad, S. K. Negin, and T. Arefeh, "A focus on the contribution of promoting TOD to increasing tehran's public spaces," Procedia Engineering, vol. 165, 2016.

[6] S. Hyungun and G. C. Chang, "The link between metropolitan planning and transit-oriented development: an examination of the Rosario Plan in 1980 for Seoul, South Korea," Land Use Policy, vol. 63, 2017.

[7] G. H. Cheng, S. C. Sun, L. L. Zhou, and G. Z. Wu, "Using Smart Card Data of Metro Passengers to Unveil the Urban Spatial Structure: A Case Study of Xi'an, China," Mathematical Problems in Engineering, vol. 2021, Article ID 9176501, 10 pages, 2021.

[8] T. Wang, Y. Wang, X. M. Zhao, and X. K. Fu, "Spatial distribution pattern of the customer count and satisfaction of commercial facilities based on social network review data in Beijing, Chinas," Computers, Environment and Urban Systems, vol. 71, 2017.

[9] M. M. I. Mohd, F. I. Ahmad, and N. H. Nordin, "Railway station facilities in rural and urban services based on observation and user feedback," MATEC Web of Conferences, vol. 47, 2016.

[10] K. Song, R. Zhou, H. Z. Lin, H. l. SU, and WANG, "Research on Optimal Method for Land Use Around Urban Rail Traffic Site-A Case Study of Wujiaochang Station on Shanghai Metro Line 10," Journal of Fudan University, no. 1, pp. 78-85, 2013.

[11] H. Hanssens, B. Derudder, S. Van Aelst, and F. Witlox, "Assessing the functional polycentricity of the mega-cityregion of Central Belgium based on advanced producer service transaction links," Regional Studies, vol. 48, no. 12, pp. 1939-1953, 2014.

[12] A. Roukouni, S. Basbas, and A. Kokkalis, "Impacts of a metro station to the land use and transport system: the thessaloniki metro case," Procedia - Social and Behavioral Sciences, vol. 48, pp. 1155-1163, 2012.

[13] T. Craig and Z. John, "Built environment and pedestrian behavior at rail rapid transit stations in bangkok," Transportation, vol. 37, pp. 317-330, 2010.

[14] L. Wu, W. Lu, and P. J. Sun, "Research OF the walking range and flow line surrounding subway HUBS: a case study of xi'an Lu station in dalian city," Architectural Journal, no. S1, pp. 22-27, 2017.

[15] P. Wood, "Urban development and knowledge-intensive business services: too many unanswered questions?" Growth and Change, vol. 37, no. 3, pp. 335-361, 2010.

[16] S. J. Huang and C. Zhang, "The influences of the agglomeration of producer services on the urban productivity: from the perspective of industry heterogeneity," Urban Development Studies, vol. 23, no. 3, pp. 118-124, 2016. 
[17] J. S. Li, Y. Liang, and X. R. Wang, "Spatial clustering analysis of service industries in Zhengdong New District based on POI data," Geographical Research, vol. 37, no. 1, pp. 145-157, 2018.

[18] D. T. Duncan, J. Aldstadt, J. Whalen, S. J. Melly, and S. L. Gortmaker, "Validation of walk score for estimating neighborhood walkability: an analysis of four US metropolitan areas," International Journal of Environmental Research and Public Health, vol. 8, no. 11, 2011.

[19] H. Peng, H. Xiong, and J. Y. Tian, "Urban area pedestrian accessibility study based on big data, Journal of Chongqing University of Technology (Natural Science)," vol. 33, no. 8, pp. 111-117, 2019.

[20] Y. Deng, "The spatial succession and organization model of the urban material space within the rail transit station: a case in beijing," Scientia Geographica Sinica, vol. 37, no. 6, pp. 817-824, 2017.

[21] L. Z. Zhang, Y. Zhuang, and Y. Ye, “A correlation analysis of transport accessibility and spatial performance aiming for synergistic development in rail transit station areas: a case study of central shanghai," New Architecture, no. 2, pp. 114-118, 2019.

[22] B. Shereen, K. Barendien, and K. Janine, "Location decision strategies for improving SMME business performance," Acta Commercii, vol. 11, no. 1, 2011.

[23] Y. J. Wang, "International studies on the interaction between urban rail transit and land use of station areas," Urban Planning International, vol. 33, no. 1, pp. 111-118, 2018.

[24] R. Cervero, Transit-oriented Development in the United States: Experiences, Challenges, and prospects, Transportation Research Board, Washington, DC, USA, 2004.

[25] Q. Zhang, B. X. Zhang, and H. Wang, "Dominance degree disparities of Chinese construction supervision enterprises," Journal of Northwest University, vol. 46, no. 2, pp. 298-302, 2016.

[26] Y. Yang, C. Wang, W. Liu, and P. Zhou, "Understanding the Determinants of Travel Mode Choice of Residents and its Carbon Mitigation potential," Energy Policy, vol. 115, 2018. 